\title{
Investigation of Nondestructive Testing Methods for Friction Stir Welding
}

\author{
Hossein Taheri ${ }^{1, *} \mathbb{C}$, Margaret Kilpatrick ${ }^{2}$, Matthew Norvalls ${ }^{3}$, Warren J. Harper ${ }^{3}$, \\ Lucas W. Koester ${ }^{4}$, Timothy Bigelow ${ }^{3,4}$ (D) and Leonard J. Bond ${ }^{3,5}$ (D) \\ 1 Department of Manufacturing Engineering, Georgia Southern University, Statesboro, GA 30460, USA \\ 2 Department of Mechanical Engineering, Georgia Southern University, Statesboro, GA 30460, USA; \\ mk03650@georgiasouthern.edu \\ 3 Department of Mechanical Engineering, Iowa State University, Ames, IA 50011, USA; \\ matthew.norvalls@gmail.com (M.N.); wjharper5@gmail.com (W.J.H.); bigelow@iastate.edu (T.B.); \\ bondlj@iastate.edu (L.J.B.) \\ 4 Center for Nondestructive Evaluation (CNDE), Iowa State University, Ames, IA 50011, USA; \\ lkoester@iastate.edu \\ 5 Department of Aerospace Engineering, Iowa State University, Ames, IA 50011, USA \\ * Correspondence: htaheri@georgiasouthern.edu; Tel.: +1-912-478-7463
}

Received: 15 April 2019; Accepted: 23 May 2019; Published: 29 May 2019

check for updates

\begin{abstract}
Friction stir welding is a method of materials processing that enables the joining of similar and dissimilar materials. The process, as originally designed by The Welding Institute (TWI), provides a unique approach to manufacturing - where materials can be joined in many designs and still retain mechanical properties that are similar to, or greater than, other forms of welding. This process is not free of defects that can alter, limit, and occasionally render the resulting weld unusable. Most common amongst these defects are kissing bonds, wormholes and cracks that are often hidden from visual inspection. To identify these defects, various nondestructive testing methods are being used. This paper presents background to the process of friction stir welding and identifies major process parameters that affect the weld properties, the origin, and types of defects that can occur, and potential nondestructive methods for ex-situ detection and in-situ identification of these potential defects, which can then allow for corrective action to be taken.
\end{abstract}

Keywords: friction stir welding (FSW); defects; mechanical properties; nondestructive testing \& evaluation (NDT\&E); in-line monitoring

\section{Introduction}

Friction stir welding (FSW) is a joining process that was first demonstrated by The Welding Institute (TWI) of Great Britain in 1991 [1]. Since that time, FSW use has soared, and by the end of 2007, TWI had issued 200 licenses for the process. Its applications continue to grow. In addition, approximately nineteen hundred patent applications have also been filed relating to aspects of FSW [2,3]. The popularity of the process can be related to the multiple advantages that FSW offers, when compared with other jointing modalities, including the ability to join vastly different metals, when performed correctly, achieve minimal defect creation, maintain much higher material strength along the bonds than typical for other joints, and provide smooth surfaces after joining.

In performing the FSW process it typically involves two metals clamped on a rigid surface that serves as an anvil together and a rotating shoulder, a mechanical "stirring" device that resembles a drill bit. The anvil serves to react the downward pressure, i.e., the plunge force, during the FSW process. By forcing the rotating shoulder into the materials along the weld interface, a frictional force 
is generated due to the high speeds and maintained downward pressure of the rotating shoulder against the metal plates. The resulting frictional heating creates a softened zone which is mechanically plasticized at the location of joining (Figure 1). The welding tool is simultaneously rotated and moved along the desired weld line, blending the materials along the path. The resulting weld is typically stronger than that given by traditional fusion welding methods because it is formed at a lower temperature, which minimizes a heat-affected zone and this also reduces distortion and resulting residual stress. In addition, FSW is an environmentally friendly process, as it does not use shielding gas or filler material and it involves minimal energy input.

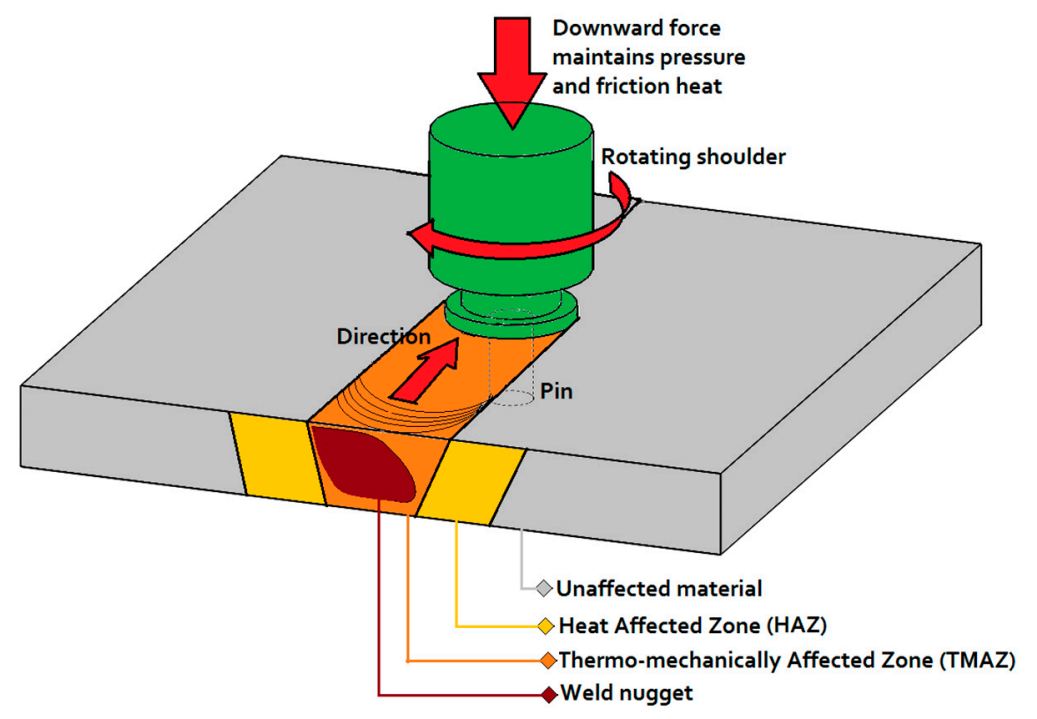

Figure 1. Friction Stir Welding (FSW) tool and system setup.

Since FSW is typically implemented in an automated process, when using correctly designed tools and parameters, defects should not occur. However, if the process is incorrectly controlled, the resulting quality of the weld can be degraded. For any material joining technique-No process is perfect, and defects can potentially occur. For FSW wormholes, kissing bonds, and defects caused by lack of penetration are the typical defects of current concern in industry [4,5]. With the use of FSW soaring, there is a need for nondestructive evaluation (NDE) processes that are superior to those currently available in the market [6] to provide adequate quality control [7], particularly for safety critical applications.

The nondestructive testing (NDT) demands by industry when FSW is used are that fast and cost-efficient methods are provided to assess the weld quality. Although welds are generally of high quality, some heterogeneity may arise due to the improper stirring of the parent material, lack of penetration of the tool pin, poor choice of tool pin design or improper choice of the process parameter window. When defects do occur, they are very different in form from those typically found in a conventional fusion welding process.

A further constraint, in terms of inspection needs, is that the FSW method is typically a high-end fabrication method. Destructive evaluation of such welds in most cases is not recommended for evaluating quality since they are costly, in terms of lost items, and time consuming to conduct [8]. When used destructive examination techniques generally involve bending tests and metallography/macrographs. In these techniques, the welded samples are removed from the original welding surface, but such samples only provide data for the region where measurements, such as micrographs, are taken. In general, evaluation of weld quality is most commonly performed post-weld using conventional non-destructive testing methods, such as X-rays, ultrasonic testing, eddy current and dye penetrant, although the later are limited to detecting surface defects. The specific type, size, 
shape and orientation of a defect all affect the detectability and characterization of the specific anomaly, and this depends on the specific nondestructive method used [7,9].

Several articles have reviewed different aspects of FSW, such as the joining of dissimilar materials [10-12], FSW for joining particular alloys such as Aluminum and Magnesium or processes [13-15], design and details of FSW tools [16,17] and numerical analysis of the FSW process [18-20]. However, despite the importance of quality control of joints produced using FSW, there are very few articles which discuss and describe the variety of defects which can occur in FSW and the non-destructive testing (NDT) techniques that have been used or evaluated for inspection of FSW $[4,6]$. This paper introduces the different types of defects in FSW, reviews the potential NDT techniques for use in inspection of FSW and surveys the various real-time monitoring methods for use in in-line inspection of the FSW process.

\section{Applications of Friction Stir Welding}

FSW is ideal for applications where higher strength properties are required along the welded seam. Examples of applications include those in the aircraft, marine, nuclear and the aero-space industries where extreme environments require welds to reliably have specific properties. Additionally, FSW welding typically creates stronger metallurgical bonds, it is also commonly a faster welding process, and can enable fabrication of designs that reduce the overall complexity of many components. In most cases, there is also a reduction in weight as no additional material was introduced. In the case of aircraft manufacturing, FSW is especially beneficial as the use of rivets and raised weld beads that can adversely impact the aerodynamics of the craft, can be avoided. This is especially important for supersonic craft, as the drag increases exponentially with surface roughness.

To take advantage of the benefits of using FSW, Eclipse Aerospace was one the first companies to utilize the process and implemented it on their 500 and 550 series business jets. A total of $128 \mathrm{~m}$ of friction stir welds was used on the jets and this replaced $60 \%$ of the rivets, resulting in a substantial reduction in materials used and hence overall weight. Additionally, the use of FSW saved time, as the welding process can be performed at a rate $10 \times$ faster than riveting, decreasing the time to build one airframe substantially compared to an original $5 \mathrm{~h}$. As a result of the adoption of the use of this advanced welding process, the Eclipse 500 and 550 business jets were granted approval for double the service life, as compared with the earlier versions, with an increase to 20,000 pressurization cycles. This was due to the increased strength of the airframe, which was $3 \times$ stronger than those fabricated using conventional riveting [20]. Since Eclipse started using FSW, other companies including Spirit Aerosystems, Boeing, and Embraer have all begun production of components fabricated using FSW [21]. In addition to the aerospace industries, the possibility of improved fabrication of lightweight materials makes FSW a good candidate for applications in the automotive and rail transportation fields [22].

The aforementioned is just one of the multitudes of uses for FSW in today's industries. The ability to weld dissimilar metals and composites [7] with relative ease has now driven the process to be adopted across various industries. The fact that this technique is superior in many ways compared to traditional processes is why it has been so popular and rapidly adopted in a relatively short time. FSW is a one of a kind material joining technique, which provided a new technology with significant potential for improved joining of materials. The following sections describe the most common applications of the FSW. However, it should be noted that there are a variety of other applications, which are developed for FSW such as friction stir spot welding, multi-pass FSW, tandem stir welding and bobbin welding. In this paper, the types of defects, mechanism of generation, and methods of NDT used for defect detection is discussed. For more advanced application of FSW, such as mentioned above, the NDT techniques might need to be adjusted accordingly.

\subsection{Welding of Conventional Metals}

FSW is a solid-state process that can provide improvements over conventional welding in terms of both quality and performance for a wide range of materials, specifically those which are difficult-to-weld, 
such as aluminum [23,24], and for cases involving steel [25] where mechanical properties of the FSW material compare favorably with the properties of the parent metal. Furthermore, FSW provides a lower-cost and more environmentally friendly process with less energy consumption and a more repeatable performance when compared with conventional joining [26].

\subsection{Welding of Dissimilar Materials}

One of the main advantages of FSW is its ability to join dissimilar metals and alloys where the combination might not be compatible in terms of chemical and mechanical properties when considering conventional welding techniques. This is possible because FSW does not involve bulk melting of the materials that are joined [27,28]. Joining dissimilar alloys has many different applications including in the automotive, aerospace and shipbuilding industries where FSW can be a solution to cases where there are no alternative conventional welding method available $[10,29,30]$. An example of a configuration for joining dissimilar materials with a butt joint using a friction stir welding process, representing the importance of tool offset on FSW of dissimilar materials is shown in Figure 2.

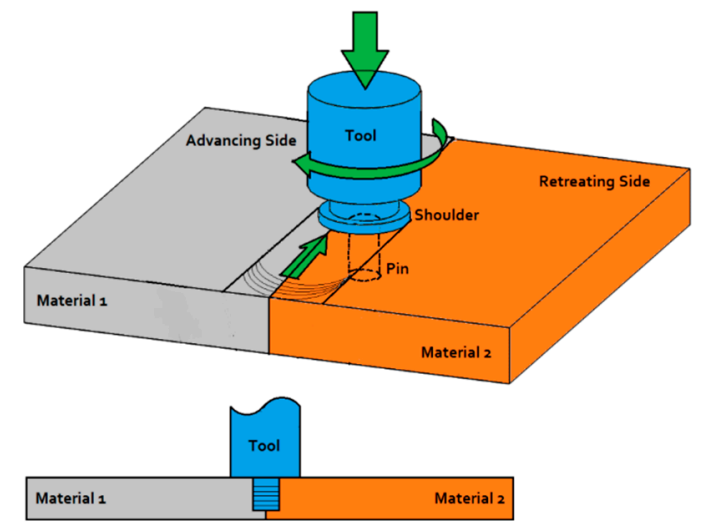

(a)

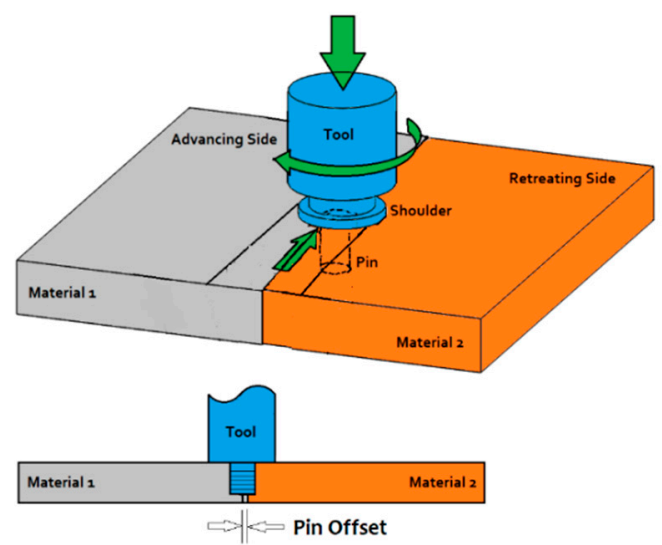

(b)

Figure 2. Schematic showing configuration for joining dissimilar materials using a friction stir welding process. (a) No tool offset, (b) Existence of tool offset.

\subsection{Friction Stir Additive Manufacturing}

Friction stir welding as a solid-state joining process can be used for fabrication of multilayer metal parts. This process works by joining metals layer-by-layer until the desired shape and thickness of the part is achieved [31,32]. The advantage of this method is that each previously added layer acts as a support for the next pass so that the structure is self-supported during the manufacturing process [32,33]. Investigations show that mechanical properties of multilayer FSW formed materials are comparable to those of the corresponding base metal. In addition, there are potentially improved mechanical properties in the weld zone' when compared to those for the base metal [32].

\section{Standard Requirement for FSW}

The application and implementation of FSW in any particular field varies depending on the specific requirements of each industry, however; there are general standards and specifications for the process. As an example some of these standards and specifications for friction stir welding of Aluminum are listed in Table 1. These specifications cover the general requirements for the FSW of aluminum alloys and they include the requirements for weldment design, qualification of personnel and procedures, fabrication, and inspection. 
Table 1. Standards and Specification for Friction Stir Welding (FSW) of Aluminum Alloys.

\begin{tabular}{|c|c|}
\hline Standard (Code) & Title \\
\hline \multicolumn{2}{|r|}{ American Welding Society (AWS) } \\
\hline AWS D17.3/D17.3M:2010 & $\begin{array}{l}\text { Specification for Friction Stir Welding of Aluminum Alloys for } \\
\text { Aerospace Applications }\end{array}$ \\
\hline \multicolumn{2}{|r|}{ EN ISO } \\
\hline EN ISO 25239-1:2011: & Friction Stir Welding_Aluminum-Part 1: Vocabulary \\
\hline EN ISO 25239-2:2011: & Friction Stir Welding-Aluminum—Part 2: Design of weld joints \\
\hline EN ISO 25239-3:2011: & Friction Stir Welding-Aluminum-Part 3: Qualification of welding \\
\hline EN ISO 25239-4:2011: & $\begin{array}{l}\text { Friction Stir Welding-Aluminum-Part 4: Specification and } \\
\text { qualification of welding procedures }\end{array}$ \\
\hline EN ISO 25239-5:2011: & $\begin{array}{l}\text { Friction Stir Welding-Aluminum-Part 5: Quality and inspection } \\
\text { requirements }\end{array}$ \\
\hline
\end{tabular}

\section{Friction Stir Welding Process}

FSW differs in many ways from a traditional welding process and other jointing processes that employ an external heat source. All heating that occurs with FSW is generated from the joining process itself. In the analysis of this process there are many variables that are related to the heat generation and input into the part during FSW such as traverse speeds, rotation speed, downward force, pin design, and the tilt angle of the pin. These variables have a dependence on the properties of the material being welded. This combination of parameters and material properties all interact and the interplay of the relationships all affect the resultant weld properties in different ways. Through the optimization of these parameters, FSW welds can exhibit high strengths, but may not always be defect free. When the process is correctly designed, the optimum parameters allow for a stick-slip wiping flow where the material flowing into the region ahead of the pin is balanced by the material flowing into the space behind the tool [34].

\subsection{Heat Generation}

FSW differs greatly from other welding processes in that there is no external heat source and all of the heat involved in the joining process is generated through the tool-material interaction. The tool action on the workpiece generates considerable stress and strain at the tool-workpiece interface. The heat is primarily generated by high shear stresses and strain rates in the material at the tool/workpiece interface [2]. For a given alloy and plate thickness with a particular tool, the primary operating process variables which affect the heat generation phenomena are the pin geometry and then the downward force, tool plunge depth, rotation speed, and traverse speed. The downward force is a preset variable (if welding is not accomplished under position control), while the tool plunge depth needed is defined by sample thickness. This leaves rotation speed and traverse speed as the undefined process variables. Increased rotation speed leads to higher levels of heating and hence temperatures induced in the material (Figure 3). Tang et al. (1998) performed a test in which the tool rotation speed was varied and the resulting temperature of the weld in a 6061-T6 aluminum plate was measured for various speeds; all other parameters were kept constant. At a tool rotation speed of $300 \mathrm{rpm}$, a temperature of $425^{\circ} \mathrm{C}$ was recorded. An increase to $650 \mathrm{rpm}$ resulted in a $40^{\circ} \mathrm{C}$ increased to $465^{\circ} \mathrm{C}$, and a further increase in speed to $1000 \mathrm{rpm}$ resulted in a further increase of $20^{\circ} \mathrm{C}$ to $485^{\circ} \mathrm{C}$ [35]. Variation in the second key parameter, the transverse speed, is found to directly impact weld quality. There is an optimal set of speed conditions with degraded welds occurring when the speed is either too slow or too fast. When the transverse speed is too fast, occurrence of defects is common because the pin moves too fast to give the time needed to properly mix the material and to generate the needed 
level of heat input. A slow traverse speed will create too much heat within the weld and lead to different forms of defects, knows as flash or voids [36].

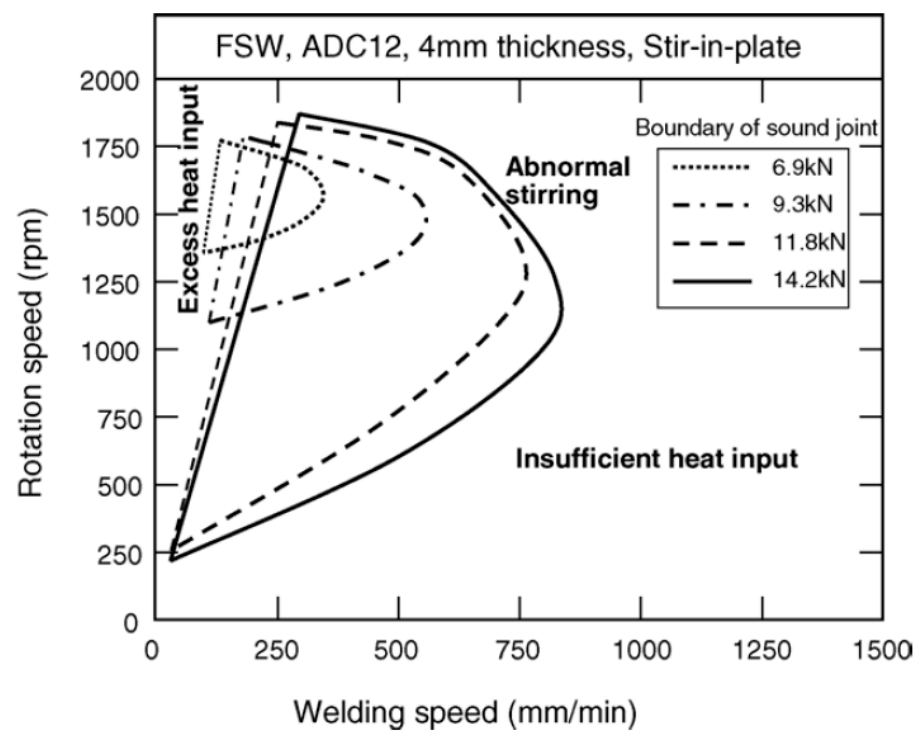

Figure 3. Tool rotation versus traverse welding speed showing heat generation. Reproduced with permission from [37], Elsevier, 2006.

\subsection{Tool Properties}

Tool properties such as geometry play a critical role in determining material flow and it controls what is the optimal transverse speed for good quality weld formation $[38,39]$. The tool is designed with a shoulder and a pin, as shown in Figure 1 and it has two main functions: to control the material flow and generate heat. The pin and shoulder can be any one of multiple designs which have been developed to encourage the formation of the desired microstructure and resulting mechanical properties. More modern tools are designed so as to reduce displaced volume. For example the MX Triflute pin reduces displaced volume by $60 \%$ when compared to earlier conventional pins [40]. The advances in design of this tool reduces welding force, enables easier flow of plasticized material, creates downward auguring, and decreases the interface area between the pin and the plasticized material [40]. Additional tool designs have been investigated so as to be able to perform various functions during welding [41,42]. In producing a tool design a combination of life and performance parameters also need to be considered for a FSW processes so as to minimize the equipment costs associated with the process [43].

\subsection{Effect of Anvil Back Plate}

Anvil back plates have a significate effect of properties of FSW due to the interaction with the plunge force as well as influence on heat dissipation of the process. The influence on heat dissipation will affect the microstructure evolution in the weld nugget and thermomechanically affected zone. For example, the conventional steel anvil back plates have a high thermal conductivity, which increases the dissipation of the generated heat [44].

\section{Mechanical Properties}

There are a large number of studies which have been performed to evaluate mechanical and material properties in the weld resulting from use of FSW. These have included using experimental, modeling and optimization methods [22]. 


\subsection{Strength and Ductility}

Many studies have been performed testing the ductility, tensile, and yield strength of material in FSW welds, and the results are found to vary based on the FSW process parameters, post weld heat treatments, and the materials involved. Mahoney et al. (1998) [24] tested the mechanical properties of 7075-T651 aluminum using tensile specimens prepared in both transverse (across weld) and longitudinal (along weld nugget) orientations. The longitudinal orientation samples retained 85\% tensile strength, $65 \%$ yield strength, and an equivalent elongation, when compared to base material. A post-weld ageing treatment was reported to further decreased elongation and tensile strength but it restored yield strength. The transverse orientation samples maintained $75 \%$ tensile strength, $55 \%$ yield strength, but only half the elongation. It is not unexpected for the transverse orientation to have lower values for mechanical properties, as it encompasses material from all the weld zones [24]. These results have been verified in other studies and they are consistent with other reports that FSW materials typically maintain $80 \%$ tensile strength and approximately $60 \%$ yield strength when compared to the base metal properties. However, these data do not take into account the effects of various potential cooling processes, different process parameters, and the use of different combinations of materials [45].

When performing destructive tests and breaking the weld apart for the weld areas as defined above, the strength metrics were almost constant in the weld nugget; the yield strength being $~ 80 \%$ of the value for base materials and the ultimate strength was close to $100 \%$ with an addition improved ductility. These properties are directly related to the grain size and structure in the weld nugget material. When moving into the thermo-mechanically affected zone (TMAZ) the structure retains strength but losses ductility. Finally, the heat affected zone (HAZ), as commonly found for many processes, is the weakest zone for the weld. In HAZ material, the tensile strength can vary significantly with resulting values as low as $\sim 60 \%$ of the base material and consistently low ductility has also been reported [46]. It has further been reported that the strength and ductility for the advancing and retreating sides of the weld are different, with the retreating side exhibiting lower strength [40], and this is consistent with fractures always being found to occur on the retreating side, in transverse cut samples [47,48].

\subsection{Fatigue}

With increasing use of FSW in industries, where fatigue life is of high importance, there has been a lot of research to investigate fatigue properties and factors affecting fatigue life. When reviewed, it is apparent that a few important observations have been reported, which are worth a mention. The fatigue strength of the FSW weld material is lower than that of the base metal, thus the weld is susceptible to being the site for fatigue crack initiation $[49,50]$. FSW butt welds have higher fatigue performance, which generally exceeds that of comparable fusion welds for many alloy grades, and this is due to the refined microstructure characteristics, which are found in FSW material [50,51]. Surface finish also has a significant effect on fatigue life. The FSW process leaves a grooved surface, which creates the possibility for crack initiation on the surface. In one study, Hori et al. (1999) [48] removed $0.5 \mathrm{~mm}$ from the bottom and top sides of a weld in materials for use in subway rolling stock. This machining resulted in observed strength increases in transverse and longitudinal material samples, which provided results similar to the measured strength of the base metal. Furthermore, when Magnusson et al. (2000) [50] removed a $0.5-15 \mathrm{~mm}$ layer from the top side by milling, he also found a significant improvement in the fatigue life [52]. Similar results were found with various aluminum alloys including 6013, 2014 and $7475[50,51]$. It is noted that other factors also affect sample fatigue life, especially any residual stress, the microstructure, and presence of defects which must also be accounted for when making fatigue life comparisons [53,54].

\subsection{Residual Stress}

Residual stresses are self-equilibrating forces in materials which occurred even in the absence of external loads [55]. Residual stresses can have either detrimental or beneficial effects on structural 
integrity and performance of the parts based on the location and exact nature of the stresses. Since the magnitude of residual stresses can be as high as the yield strength of the materials, evaluation of residual stresses found in FSW joints is crucial [56].

\subsection{Hardness}

The mechanical properties of joints can be evaluated by measuring the hardness distribution. In the case of FSW joints, measurements of the Vickers hardness is an appropriate method since values can vary significantly over the region investigated [57]. It has been shown that dissolution and growth of the precipitates during the thermal process of FSW can affect the hardness and consequently joint efficiency [58]. Most of the hardness evaluations have been performed by first monitoring temperature during FSW and then evaluating subsequent data in terms of its relationship to the microstructure and hardness distributions. At higher temperatures (573 K in case of AA2024-T3), precipitates were found to have started to dissolve and consequently the heat affected zone (HAZ) loses its hardness, resulting in a reduction of joint efficiency. Precipitate growth time can be decreased by increasing the heating rate and this then causes hardening in the HAZ [58].

\subsection{Weld Microstructure}

The degree of heat generation which occurs during the joining process greatly alters the resulting microstructure with four separate areas resultant when the material is examined and these are defined by the American Welding Society (AWS) as:

1. Base metal or unaffected metal: parent metal in which the microstructure and mechanical properties are the same as before the welding process.

2. Heat affected zone (HAZ): volume close enough to the weld for thermal effects to modify the microstructure and/or mechanical properties but with no plastic deformation.

3. Thermo-mechanically affected zone (TMAZ): This zone is identical to the HAZ but has plastic deformation. Recrystallization does in general occur but not for aluminum alloys.

4. Stir zone: the area along the weld nugget in which the process passes through, recrystallization occurs for all materials in this zone [4].

The weld nugget material is typically recrystallized and it has a fine and equiaxed grain microstructure. There are also two shapes of the nugget zone: a basin shape that opens at the top and an elliptical shape. Mishra et al. (2005) [39] reported that a basin shape is an artifact which results from a lower tool rotation speed, typically between 300-500 rpm and an elliptical shape is due to a tool rotation speed greater than $700 \mathrm{rpm}$ [40].

It is worth noting that a circular pattern called 'onion rings' are often seen in metallographic cross sections in the weld nugget. The variations seen in the ring pattern, according to Mishra et al. [40], are due to differences in dislocation density and texture effects. This is not believed to be a complete explanation for the rings, but it is further thought that they are associated with effects due to the rotation of the tool, as well as being associated with the direct function of tool geometry, and process rotation and traverse travel speeds [40,59]. Notably, in aluminum materials subject to FSW, crystallization occurs within the weld nugget and it isn't unusual to finish with equiaxed grain sizes on the order of a few micrometers. It is also possible to control grain size by use of external cooling or altering various process parameters. In metallographic examinations, it is common to see larger grains at the top of the weld due to the effects of heat dissipation through the backing plate and as a result of the lower peak temperatures at the bottom of the weld $[40,60]$.

\section{Types of Defects}

With adequate process control, the FSW process is often capable of effectively eliminating, or at least significantly reducing, the occurrence of many of the defects, which are associated with fusion welding techniques such as shrinkage, solidification cracking and porosity. However, as in any weld, 
some defects can occur which are dependent on the joint geometry (butt or lap), but each type of defect does not affect the material in the same way and therefore must be understood if it is to be identified and then prevented by process modifications [61]. There are still various types of defects that can occur during the FSW process irrespective of the welding orientation.

\subsection{Wormhole}

Wormhole defects are in the form of voids or trailing voids left in the material after the welding process. Such defects are caused by abnormal material flow conditions during welding resulting from sub-optimal combinations of numerous factors including stirring rotational speed, traverse speed, resulting heat generation, and shoulder pressure. This type of defect can be prevented by using pins with a design optimized to match the weld material and thickness or adjusting the welding process parameters [62,63]. Kahl (2013) [45] evaluated the occurrence of wormhole voids along the weld nugget in 6061-T6 aluminum and observed a decrease of $10 \%$ of tensile strength and a large reduction in elongation when wormholes occur. For the same material fatigue testing between 42.5-57.5 MPa stress amplitude the samples exhibited a decrease of $\sim 20 \%$ in lifetime for those welds which contained small voids [45].

\subsection{Lack of Penetration (LOP)}

Lack of penetration (LOP) defects are found in butt welds, where the lower portion of the joined interface is only partially disrupted (Figure 4). This is caused by the FSW pin not being long enough to penetrate both materials effectively, and it can be prevented by using a pin design which is optimized for the specific weld application and by keeping the shoulder of the tool flush with the material surface [64].

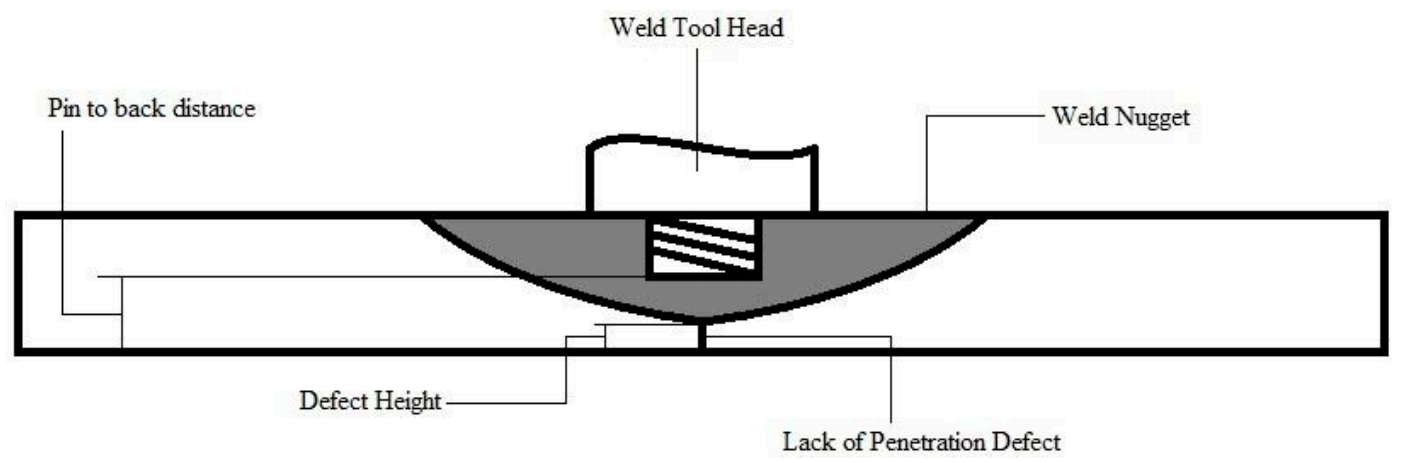

Figure 4. Lack of penetration defect where the pin does not penetrate material completely.

An example of LOP defects, which were caused by change in welding tool rotational speed and pressure (load), are seen in the metallography of $3.175 \mathrm{~mm}$ (0.125 in) thick Aluminum 7075-T73 panels shown in Figure 5 [65].

\subsection{Partial and Kissing Bonds}

Partial and kissing bonds (KB) typically occur in the root of the weld. This type of defect arises when two adjacent surfaces are in close contact, but never form a full metallurgical bond [66], giving reduced strength. The kissing bond can have surfaces in contact and no metallurgical joining. This is due to insufficient deformation of the joining surface interface due to incorrect tool design, lack of penetration, poor surface preparation, residual stress, contamination, or some combinations of these factors [67]. The effect of KB on the static strength of the weld can be negligible, and depends on the application. However, KB defects can significantly reduce the fatigue life depending on the size of the KB defect area [68]. For example, Kadlec (2015) [46] performed mechanical testing to investigate the effects of the KB defects on tensile and fatigue properties of 7475-T7351 friction stir welds against welds without any flaws. Various KB defects were investigated by Kadlec with the aim of evaluating which 
defect geometry has no influence to the fatigue life of joined $6.35 \mathrm{~mm}$ thick plates. A critical value for KB geometry seemed to be $0.3 \mathrm{~mm}$ in depth considering influence on fatigue life for investigated configurations. It was reported that samples with shorter kissing bonds allowed higher elongation values and higher tensile strength. It was also reported that when a kissing bond 'open ups', it caused fracture before necking could start. This study showed the detrimental effects of having kissing bonds in welds in structure materials [46]. When using conventional NDT techniques the detection and determination of an accurate size for the KB defect is a difficult task.

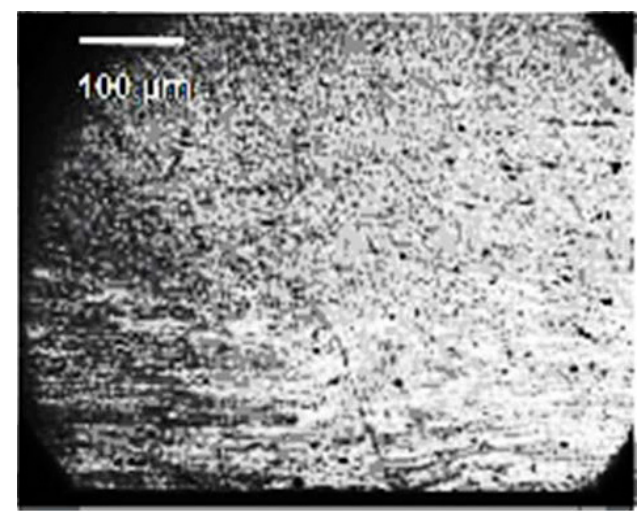

LOP Depth (inches) $=0.0097$

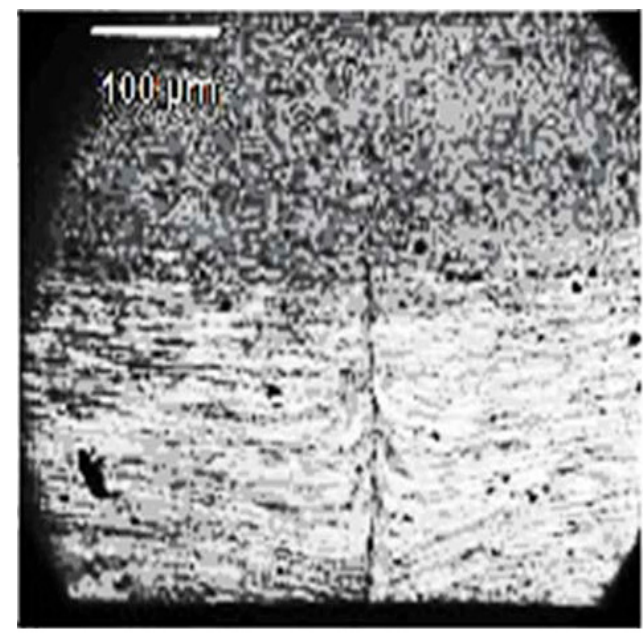

LOP Depth (inches) $=0.0122$

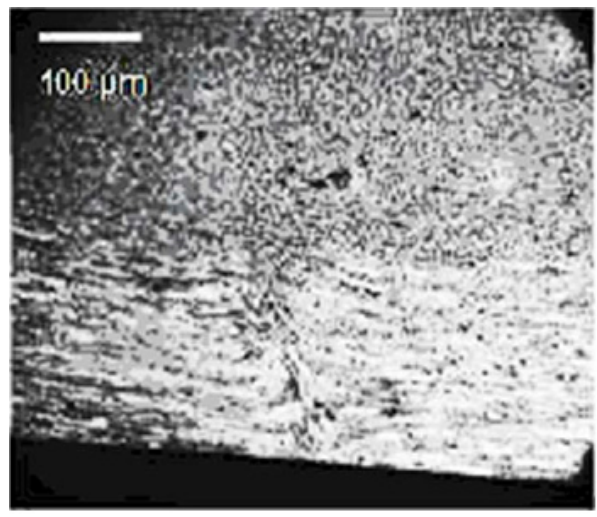

LOP Depth (inches) $=0.0102$

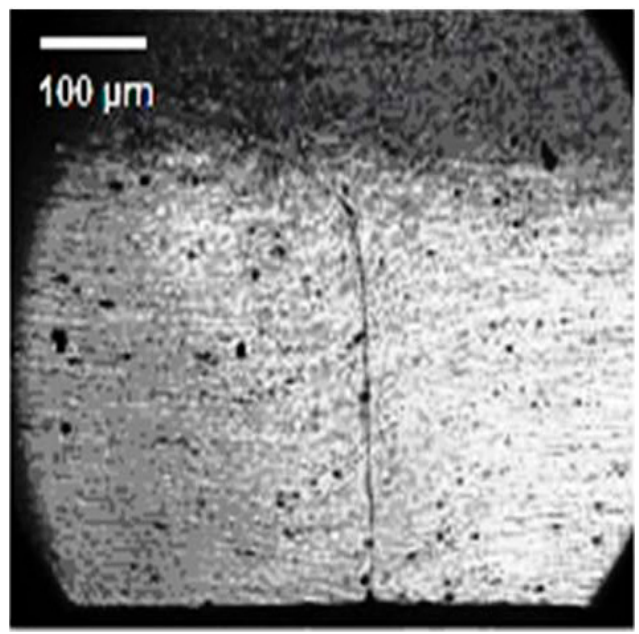

LOP Depth (inches) $=0.0210$

Figure 5. Metallography of lack of penetration (LOP) defects in $3.175 \mathrm{~mm}$ (0.125 in) thick AL 7075-T73 panels. Reproduced with permission from [69], Taylor \& Francis, 2019.

\subsection{Hooking Bonds}

Hooking Bonds are defects that are specific to lap joints, and they are formed when the interface between the two adjoining sheets is stirred up into the top sheet, which effectively reduces the cross-sectional area of the sheet. It is found that the two main causes of hooking defects are lower transverse welding speed and higher rotational speed. Such defects can be prevented with double passing welds and by overlapping the advancing sides [21]. In designing a welding system the appropriate geometry and shape of the FSW tool should be obtained to minimize potential for this defect in the bottom sheet of a lap joint [70]. 


\subsection{Cracks}

Cracks can be generated in the welding zone of FSW by various factors. Among the causes of cracking are excessive local load and stress concentration that can generate cracks in the welding area due to high thermal stresses [51]. Resulting residual stresses and heat-affected zone properties can also influence crack formation and propagation in FSW joints [51]. Furthermore, development of the microstructures which occur in the weldment during the FSW process affects crack growth due to both corrosion or fatigue [71]. Another mechanism involved with crack generation in FSW is Liquid Penetration Induced (LPI) cracking. The liquid penetration induced cracking mechanism has been studied for a variety of alloys and situations. For example, Yamamoto et al. (2007) [72] explained that LPI cracking in magnesium alloy AZ91 results from the following sequence of events: melted eutectic film formation in the periphery of the stir zone region, subsequent engulfing of melted eutectic films when the stir zone grows in width during the dwell period, and then penetration of $\alpha-\mathrm{Mg}$ grain boundaries in the stir zone extremity and crack propagation when torque is applied by the rotating tool $[72,73]$.

\section{Material Evaluation and Quality Control of FSW}

Increasing and widespread industrial application of FSW is still limited by the potential risk for generation of defects that can occur during the process. Consequently, the ability to reliably detect relatively small flaws and determine associated mechanical properties are important for quality control and in the definition of acceptance standards for FSW joined material. To define what types and sizes of acceptable anomalies are, a variety of techniques can be employed for the evaluation of the quality of FSW joints and associated mechanical properties. These techniques can be categorized into both destructive and nondestructive methods.

\subsection{Destructive Testing and Evaluation Methods}

Variations in the FSW process parameter directly affect the microstructure and mechanical properties of the resulting joint [74]. For the material, the stress-strain curve and Young modulus of the FSW can be determined by conventional tensile tests. Either standard flat or cylindrical dog-bone shape samples are used for these tests. In case of FSW, flat dog-bone shape samples are being used. Tensile, bending and fatigue performance of the FSW material are subjected to different loading conditions and the resulting data are used to understand the mechanical behavior of the joints [75-77]. Metallographic examinations can also reveal details of microstructure and some types of defects in FSW material such as lack of penetration and kissing bonds [64].

\subsection{Non-Destructive Testing and Evaluation Methods for FSW}

As with other forms of welds, a range of nondestructive testing (NDT) methods have been used extensively to detect and characterize flaws in FSW joints. Application of each NDT method depends on knowledge regarding the desired application, needed joint and material properties, possible types of defects and geometry of the joint and specimens [78]. Also, in assessing effectiveness of an inspection method, the detectability or Probability of Detection (POD) for each method and class of defects needs to be evaluated.

\subsubsection{Radiography (X-Ray Imaging and Computed Tomography (CT))}

X-ray radiography produces images that are potentially useful for detecting defects when there are significant differences in radiation absorption between an anomaly and the surrounding parent material. Thus, when the digital detector measures variations in radiation flux these are displayed as darker or lighter regions on the displayed image which correspond to regions of either higher or lower absorption. For larger and complex parts in many metals, this method has penetration limitations 
which vary with the different absorption coefficients of the materials. The penetration capabilities also depend on the power of the X-ray system and inspection time employed.

In general terms, radiography works well for detecting volumetric flaws, of certain classes, after production, but is be difficult and costly to implement into an in-line manufacturing process [69,79]. Examples of successful applications include work by Saravanan et al (2014) [80] who used a micro-focused X-ray imaging technique to detect micro-pores and voids in FSW of dissimilar material lap joints $(150 \times 100 \mathrm{~mm}$ ), which were fabricated using $2 \mathrm{~mm}$ thick aluminum (grade 6061) and zinc coated steel (SS 316) sheet of $1 \mathrm{~mm}$ thickness [80]. Gray et al. (2008) [65] demonstrated X-ray radiography for detection of wormhole defects in different FSW sample panels [65]. The wormholes detected were as small as $0.0017 \mathrm{~mm}^{2}$ in $6.35 \mathrm{~mm}\left(0.25\right.$ in) thick panels and $0.001 \mathrm{~mm}^{2}$ in $3.175 \mathrm{~mm}$ (0.125 in) thick panels and examples of such features are shown in Figure 6. The sizes of the defects were measured by metallography and are categorized as "very small: $0.0007 \mathrm{~mm}^{2}$ ", "small: 0.001 $\mathrm{mm}^{2}$ ", and "large: $0.0472 \mathrm{~mm}^{2}$ ". However, it was mentioned that the shape and size of the welded parts and surface finish are in general the most challenging factors limiting defect detection when using a radiography technique. The assessment of the POD versus defect size characteristic is also challenging to estimate, particularly due to the effects of the complex geometric nature of the welds and the difficulty faced with reliably identifying and determining the size of defects.

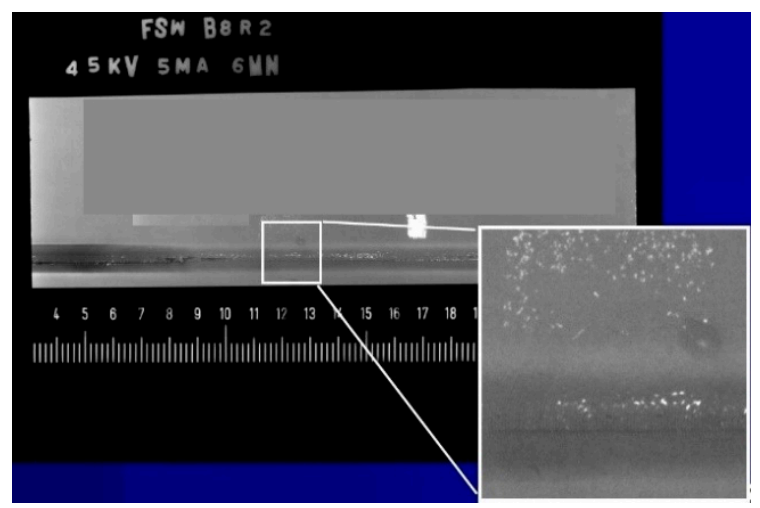

(a)

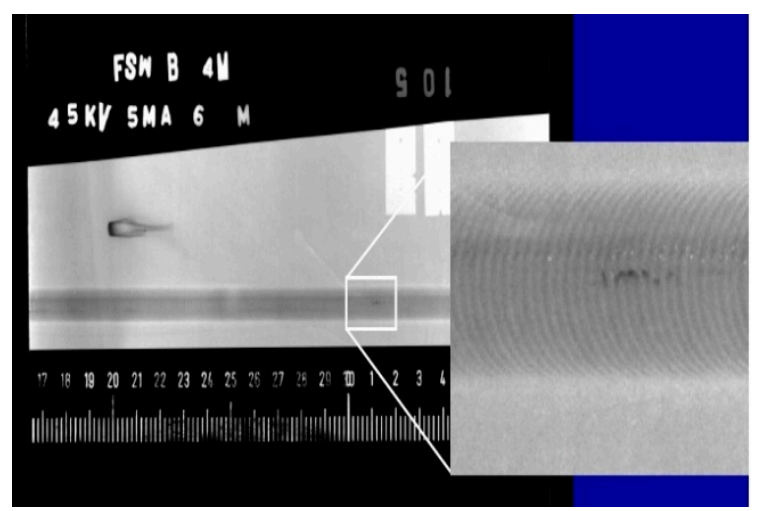

(c)

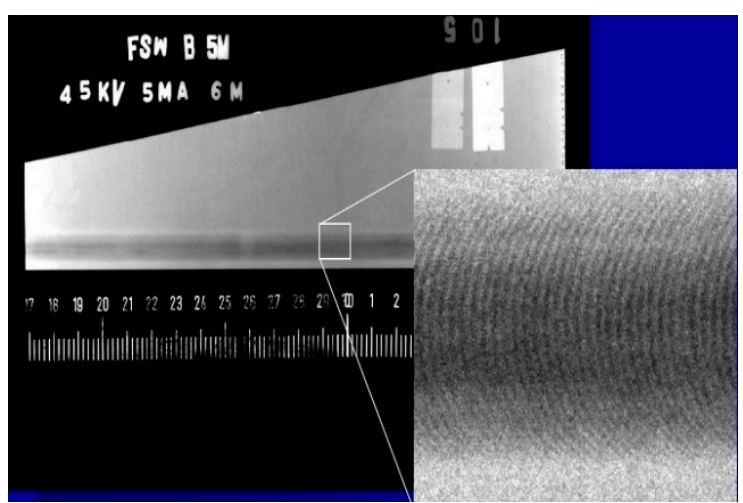

(b)

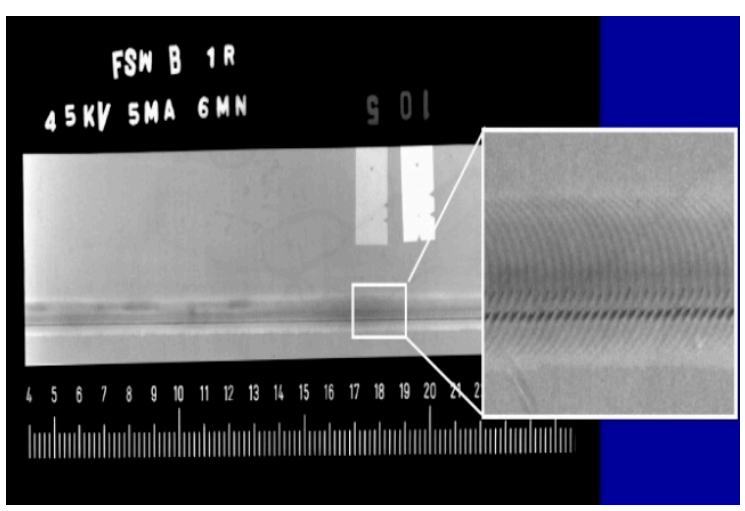

(d)

Figure 6. Inspection of friction stir welded panels using X-ray radiography method for detection of wormhole defects: (a) no defect, (b) very small defect (tiny black spots in left side of zoomed in section), (c) small defect, and (d) large defect [65].

\subsubsection{Thermography}

Thermography produces images with an inspection employing a contrast mechanism based on thermal property variations due to geometrical anomalies, material loss, inclusions, and voids. 
Thermography is a non-contact and potentially full-field methodology, making it a good candidate for in-line monitoring. Due to the heat generation mechanisms which occur in the FSW process [81], thermographic techniques can be used to find defects in real-time during the welding process [82]. In such real-time monitoring, thermal behavior of joints can be correlated to process parameters and thermography can hence be used to perform online monitoring of the FSW process. There is a possibility that this technique could be implemented to detect flaws as they are being created during welding and the FSW tool control system would then be able to potentially proactively correct defects on the part, before items move further along a production line [83].

\subsubsection{Eddy Current}

Eddy current NDT methods can be used for inspection of electrically conductive materials. A limiting factor for this inspection method is the depth of penetration of the electric field used to detect anomalies, which limits its use to detection of surface and near surface defects. Conventional and pulsed eddy current techniques can both be used for testing. In conventional eddy current testing, a sinusoidal waveform is used for excitation, while the response signals are represented on an impedance plane diagram, as changes in the resistive and reactive components of the impedance give the combined response of the coil, field and material. Pulsed eddy current measurements, in general, use a square waveform to drive the excitation coil instead of a sinusoidal wave excitation, which is more typically used in conventional eddy current testing. Generally, pulsed methods are capable of probing deeper into the material than the conventional eddy current methods. Another significant difference between conventional and pulsed eddy current measurements is that the signals in the latter case are recorded in the time domain and not on an impedance plane diagram [64,84]. New advances in eddy current probes and electronic devices now provide the capability to detect superficial defects at variety of depth depending on the frequency [85].

\subsubsection{Ultrasonic Testing}

Ultrasonic testing, in a variety of forms including acoustic microscopy have been widely used to detect and characterize defects in FSW and other solid-state welded interfaces [86,87]. In these methods, both compression and shear wave excitation have been used in various studies for inspection of FSW [88,89]. Stepinski et al. (2004) [90] prepared an excellent review on advanced ultrasound techniques for inspection of FSW with an introduction to other NDE techniques that can potentially be used and for illustrations mostly used results from the aerospace industry [90]. The main challenge which limits using ultrasonic techniques, specifically with contact and immersion methods, is the surface finish for FSW. For this reason, most inspections need to be performed with access from the back of the weld or after surface preparation, which involves a machining process. An example of the experimental setup and schematic configuration which was used by Gray et al. (2008) [65] for the ultrasonic inspection of FSW panels with wormhole defects is shown in Figure 7 [65]. The C-scan ultrasonic immersion results were obtained when using $45^{\circ}$ shear wave with a $10 \mathrm{MHz} 75 \mathrm{~mm}\left(3^{\prime \prime}\right)$ focal length probe skewed at approximately $30^{\circ}$ (azimuth) from weld line, showing examples for "very small: $0.0007 \mathrm{~mm}^{2}$ ", and "large: $0.0472 \mathrm{~mm}^{2}$ " wormhole defect sizes which could be detected (Figure 8). 


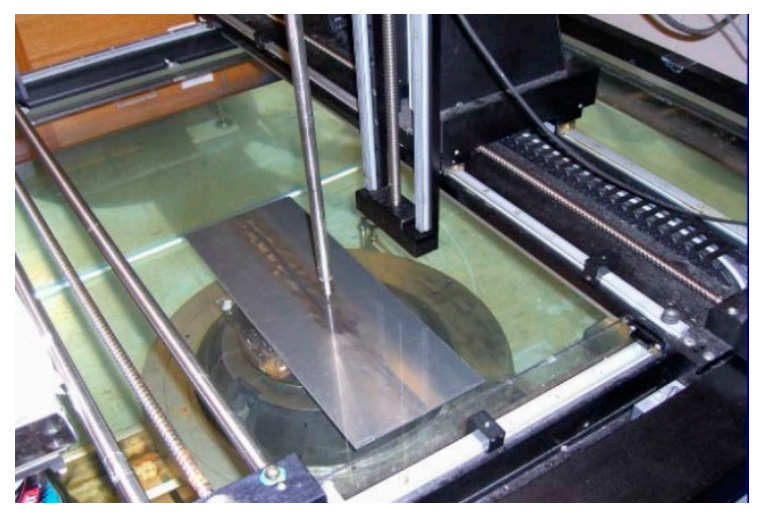

(a)

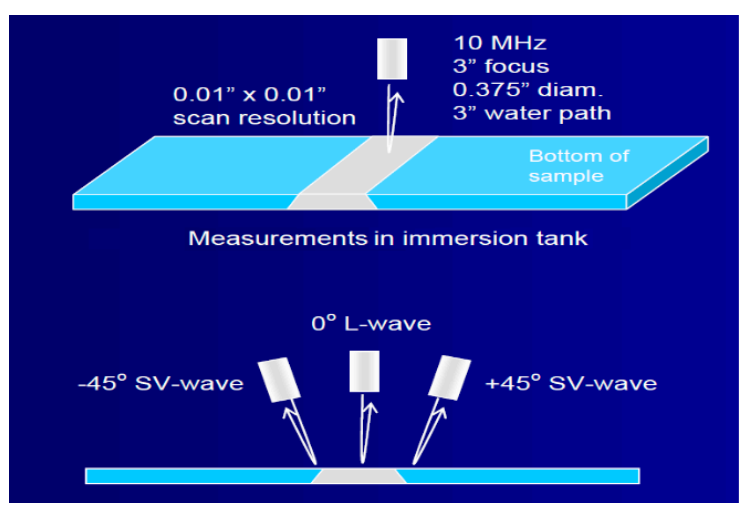

(b)

Figure 7. Inspection of FSW panels with wormhole defects (a) Experimental setup, and (b) schematic configuration for the ultrasonic inspection. [65].

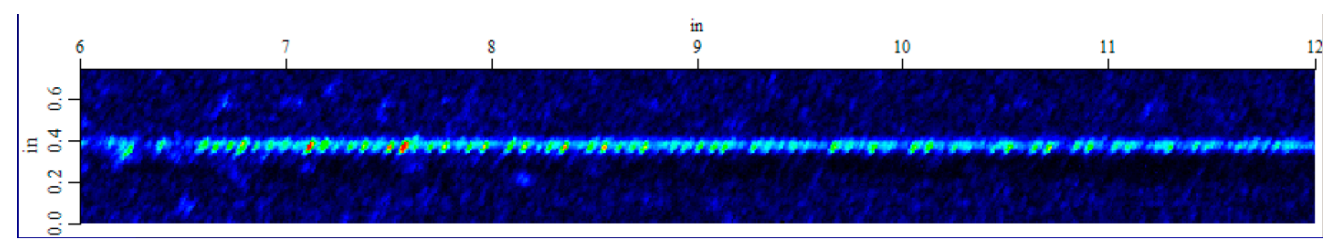

(a)

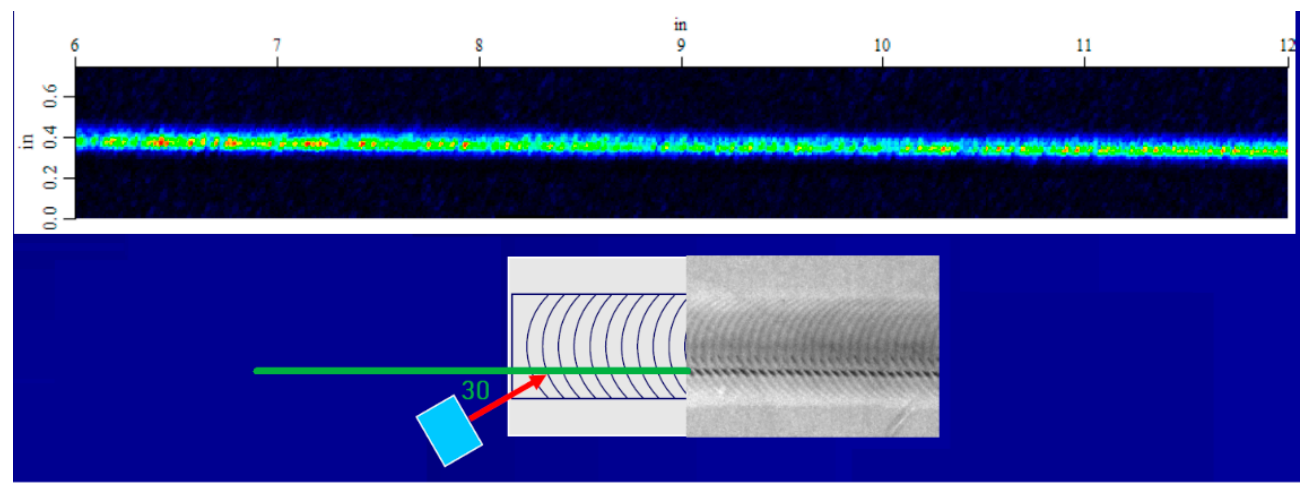

(b)

Figure 8. Immersion C-scan ultrasonic imaging at $10 \mathrm{MHz}$ using $45^{\circ}$ shear wave with probe skewed approximately $30^{\circ}$ (azimuth) from weld line for (a) "very small: $0.0007 \mathrm{~mm}^{2}$ ", and (b) "large: 0.0472 $\mathrm{mm}^{2}$ "wormhole defect sizes [65].

\section{Phased Array}

Phased array ultrasonic testing (PAUT) is a form of testing, which differs from other ultrasonic testing (UT) methods in the way the wave field is generated and detected. It employs an ultrasonic array probe that is typically composed of 16 to 256 elements, each acts as a single transducer. These elements are arranged as a string, ring, or circular matrix and can be fired singularly or together to form a designed wave front. The resulting beam can then be modified by changing the amplitude and timing of the excitation pulse sent to each element [91,92].

In implementations of PUAT there are three main electronic scanning methods: linear, dynamic depth focusing or swept angular scanning [93,94]. Swept or sectorial scanning, has proven successful in FSW applications [95,96]. PAUT has broad application in FSW quality control and inspection [79,97]. For defect detection in FSW, sectorial scanning has generally been used. This is where the beam is moved through a sweep range for a specific depth, additional focal depths can be added for the same element, which produces a shear wave. This method has been applied in the 4-10 MHz frequency 
range [98], and in process this should be targeted on the advancing side of the weld, as this is the region where defects in general form.

PAUT has gained industry acceptance as a reliable and accurate detection method and is now commonly implemented throughout industry because it potentially offers increased inspection sensitivity and good coverage, as well being applicable in near-real time. Additionally, it allows for some ease in determination of defect dimensions and shape, when compared with traditional pitch-catch methods. For example, Huggett et al. (2016) [99] utilized a $10 \mathrm{MHz} 32$ element transducer and investigated detection capabilities for accuracy, defect sizing, and effects of FSW weld configuration limitations. It was found that the PAUT system, with correct system calibration, could detect defects down to $0.15 \mathrm{~mm}$ for both length and width. However, lack of penetration defects (kissing bonds) were only able to be detected when they were $0.5 \mathrm{~mm}$ or more in height [99].

\section{Laser Ultrasonics}

An implementation of non-contact potentially in process ultrasonic testing can use lasers to generate and detect ultrasonic waves [100]. This inspection method can be used for a wide bandwidth of frequencies, up to $15 \mathrm{MHz}$. There are multiple setups for these systems, and a typical layout of laser ultrasound inspection configuration can be seen in Figure 9.

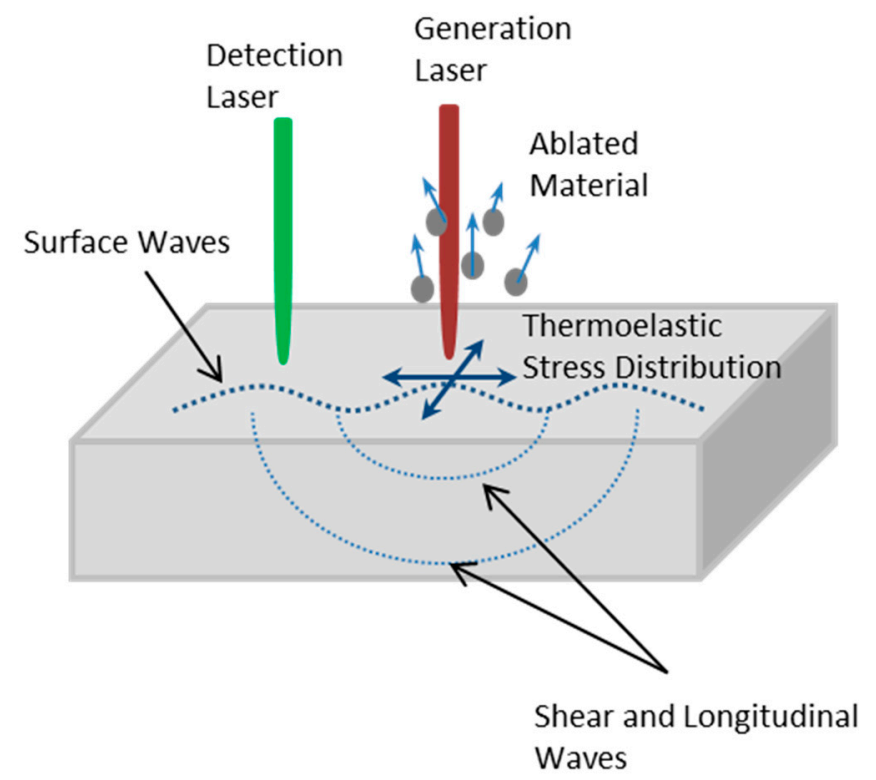

Figure 9. Schematic for laser ultrasound inspection setup (Image courtesy EWI).

A laser UT system can employ a pulsed laser for generating ultrasonic waves and a continuous laser, or long pulsed laser, coupled to an interferometer for detection, measuring surface displacements in the solid. Laser UT has the features of providing high sensitivity without using couplants, and it is suitable for detection on complex shaped surfaces and for in-line inspection.

Laser-generated ultrasonic waves can give various wave types, including surface waves that are used to inspect the specimen surface. There are two phenomena that can occur to generate waves and these are in a thermoelastic regime for lower power and ablation at high powers. With the thermoelastic mechanism the laser energy is absorbed by a material. This forms a transient temperature field with non-uniform distribution and the thermal expansion results in a stress field, giving rise to ultrasonic wave excitation. This pulse on a half space can give longitudinal, shear, and surface acoustic waves. In a plate the wave material interactions can give Lamb waves.

Laser UT can be applied in a variety of non-contact and special testing conditions such as when there are narrow spaces, parts are at high temperatures and pressures [101]. It can also be used in the presence of some degree of rough material surface or when a coating or other adhered debris is there, 
which gives it potential for use for in-line inspection, where the environment is not well controlled. That said it needs careful design and testing particularly in industrial environments and cost may be a significant limitation to implementation.

\section{Nonlinear Ultrasonics}

A traditional view of nonlinear ultrasonics is that it is associated with classical ideas of elastic wave distortion due to material nonlinearity: waveform deformation caused by a local velocity variation accumulates with propagation distance and provides progressive transition of a harmonic wave into sawtooth- or N-type waves. As a result, the spectrum acquires higher harmonics of the fundamental frequency which deliver information on the matter [102,103]. Under some conditions the nonlinear part of the stress-strain diagram is a sensitive indicator of the presence of defects.

Nonlinear ultrasonic techniques are based on the analysis of amplitude dependent wave propagation characteristics, such as harmonic generation, nonlinear wave speed and nonlinear attenuation, created by wave-defect interactions [67]. For some classes of defects these techniques have proven to be far more sensitive to emergent damage than conventional ultrasonic methods. However, inducing nonlinear behavior depends both on the local phenomena described by a more complex equation of state (through the nonlinear material properties) and on the internal stresses. The non-linear response of defects such as kissing bonds will only be activated when the local ultrasonic wave amplitude is sufficiently large to induce clapping and ratcheting of the imperfectly bonded interfaces. As such, nonlinear ultrasonic methods generally require higher excitation amplitudes ("finite" amplitudes), which as can potentially be achieved by focusing. Nonlinear UT is seeing increased use and has potential for detecting and characterizing some types of defects in-line. Non-linear acoustic methods have already been demonstrated, as being useful to identify possible FSW defects such as kissing bonds [104].

\subsubsection{Liquid Penetrant}

In liquid penetrant or penetrant testing (PT) inspection methods, a special fluid commonly red or fluorescent, is applied to a surface and with appropriate dwell times it wicks into surface breaking cracks. After removal of excess fluid from the surface a developer is applied, commonly white, which then draws penetrant (typically red) out from the cracks providing a map of red lines over the surface breaking cracks against the white background [105]. One of the advantages of PT is that it can provide a relatively low-cost inspection of surface-breaking defects in a wide variety of materials. Liquid penetrant inspection can be used successfully on nonporous and fairly smooth materials such as metals, glass, plastics and fired ceramics. The test is very effective in detecting porosity, cracks, fractures, laps, seams and other flaws that are open to the surface of the test piece. A variety of penetrant materials are available and selection is often based on the required sensitivity level of the test, equipment available at the test site. The inspector is a critical element in the inspection process and achieving a good probability of detection requires attention to detail.

As discussed in this section, the objectives of applying NDT techniques are to ensure the quality of FSW when considered against a given specification including defined acceptance criteria. Many non-destructive testing (NDT) techniques are potentially effective in testing FSW components as described above. Each of these techniques is based on different physical principles to detect defects on the surface of the part or throughout its whole volume. However, the geometry, surface condition, physical and material properties of the part being tested are key factors in determining the applicability and performance of a given NDT technique and these need to be considered for any particular post-fabrication application [106].

\section{In-Line Monitoring for the FSW Process}

In addition to the various activities which consider development, optimization and evaluation of FSW process, tool design, post-weld properties and quality control, strict process monitoring and 
control is necessary for effective deployment of the process. Process monitoring and control of FSW provides potential for the capability of fault diagnosis in process or defect generation detection in the weld during welding and hence offers the potential of remedies which can be considered before a weld that has unacceptable quality is completely manufactured [107].

Several different monitoring methods and evaluation techniques have been considered and evaluated for inline monitoring of FSW. These methods either directly monitor the characteristic signals from the weld process such as weld zone temperature [36], acoustic emission signals [108,109] or the tools parameter, such as wear [110], torque and traverse force [111] and how each of these parameters relate to weld quality. For example Jene et al. (2008) [112] showed that by monitoring the welding force, reliable feedback is obtained which can be used to control the welding process parameters and minimize or even prevent formation of flaws in FSW [112].

In seeking to improve process control, different data analysis and signal processing techniques have been used for processing of monitoring data based on the various characteristic signals. The force footprint of the tools and temperature profile of the weld zone are among the main characteristic signals used. Analyzing related data provides a better understanding of the influence of certain key process parameters on resulting weld properties, through their monitoring and feedback into process control during the welding process $[113,114]$. In seeking to better understand the process a range of image processing techniques have been extensively used with various data types and correlated to studies of the quality of weld based on captured images from the weld zone and destructive tests $[115,116]$. Applications include cases where statistical signal processing was carried out to determine whether the force signals could be correlated with defects generated and used to develop an automatic fault detector/classifier in FSW process $[117,118]$.

\section{Summary}

Despite the excellent weld quality, which can generally be produced by friction stir welding, the joining process is unlikely to provide welds that are completely free of defects. To ensure quality welds, particularly in critical applications, this defines the need for enhanced inspection and control of FSW. In particular, nondestructive evaluation and process certification linked to application of reliable inspection techniques and inline monitoring methods are of paramount importance. To provide application of NDE and in-situ monitoring techniques there is a critical need for a good understanding of types of defects which can potentially occur in FSW. The current state of the art is such that several NDE techniques are identified with potential for application that can enhance weld quality, particularly when linked to understand of defect formation and on-line process control.

Author Contributions: All the authors wrote the paper.

Funding: This research received no external funding.

Acknowledgments: Some of the NDE data and FSW samples were prepared with support from an NSF TIE Project between CNDE and SASM\&T (South Dakota School of Mines and Technology) and the authors thank Tim Gray, Terry Jensen, Mike Garton, Mykal Clayton and Nate Richter (NSF REU Funding) for previously unpublished results that were originally presented in a report the CNDE Sponsors, when it was an NSF IUCRC.

Conflicts of Interest: The authors declare no conflict of interest.

\section{References}

1. Thomas, W.M.; Murch, M.G.; Nicholas, E.D.; Temple-Smith, P.; Needham, J.C.; Dawes, C.J. Improvements Relating to Friction Welding. Google Patents EP 0653265 A2, 17 May 1995.

2. Threadgill, P.L.; Leonard, A.J.; Shercliff, H.R.; Withers, P.J. Friction stir welding of aluminium alloys. Int. Mater. Rev. 2009, 54, 49-93.

3. Thompson, J.M. Friction Stir Welding Machine and Method. U.S. Patent 6302315 B1, 16 October 2001.

4. Podrzaj, P.; Jerman, B.; Klobčar, D. Welding defects at friction stir welding. Metalurgija 2015, 54, 387-389.

5. Kah, P.; Rajan, R.; Martikainen, J.; Suoranta, R. Investigation of weld defects in friction-stir welding and fusion welding of aluminium alloys. Int. J. Mech. Mater. Eng. 2015, 10, 1-10. [CrossRef] 
6. Kinchen, D.G.; Martin, L.; Space, M.; Orleans, N.; Aldahir, E. NDE of friction stir welds in aerospace applications. Insp. Trends 2002, 1, 1-7.

7. Cerniglia, D. A Case Study on the Evaluation of Friction Stir Welds by Ultrasonic Inspection Technique. In Proceedings of the 14th International Symposium on Nondestructive Characterization of Materials (NDCM 2015), Marina Del Rey, CA, USA, 22-26 June 2015; p. 308.

8. Sagar, S.P.; Miyasaka, C.; Ghosh, M.; Tittmann, B.R. NDE of friction stir welds of Al alloys using high-frequency acoustic microscopy. Nondestruct. Test. Eval. 2012, 27, 375-389. [CrossRef]

9. Bond, L.J.; Baquera, M. Ultrasonic sizing and imaging. In ASM Metals Handbook; ASM International: Materials Park, OH, USA, 2018; pp. 291-321.

10. Murr, L.E. A review of FSW research on dissimilar metal and alloy systems. J. Mater. Eng. Perform. 2010, 19, 1071-1089. [CrossRef]

11. Mehta, K.P.; Badheka, V.J. A Review on dissimilar friction stir welding of copper to aluminum: Process, properties, and variants. Mater. Manuf. Process. 2016, 31, 233-254. [CrossRef]

12. Song, Y.; Yang, X.; Cui, L.; Hou, X.; Shen, Z.; Xu, Y. Defect features and mechanical properties of friction stir lap welded dissimilar AA2024-AA7075 aluminum alloy sheets. Mater. Des. 2014, 55, 9-18. [CrossRef]

13. Muruganandam, D.; Balasubramaniyan, C.; Gokulachander, B. Review paper on friction stir welding of aluminium and magnesium alloys. Indian J. Sci. Technol. 2015, 8, 6-11. [CrossRef]

14. Salih, O.S.; Ou, H.; Sun, W.; McCartney, D.G. A review of friction stir welding of aluminium matrix composites. Mater. Des. 2015, 86, 61-71. [CrossRef]

15. Khan, H.A.; Li, J.; Shao, C. Analyses of friction stir riveting processes: A review. J. Manuf. Sci. Eng. 2017, 139, 090801. [CrossRef]

16. Rai, R.; De, A.; Bhadeshia, H.K.D.H.; DebRoy, T. Review: Friction stir welding tools. Sci. Technol. Weld. Join. 2011, 16, 325-342. [CrossRef]

17. Heideman, R.J.; Scott, J.W.T.; Smith, C.B.; Thessin, T.M.; Ranganathan, B.N.; Bishofberger, D.F. Friction Stir Welding Tool. U.S. Patent 6053391 A, 25 April 2000.

18. He, X.; Gu, F.; Ball, A. A review of numerical analysis of friction stir welding. Prog. Mater. Sci. 2014, 65, 1-66. [CrossRef]

19. Neto, D.M.; Neto, P. Numerical modeling of friction stir welding process: a literature review. Int. J. Adv. Manuf. Technol. 2013, 65, 115-126. [CrossRef]

20. Mehta, M.; Reddy, G.M.; Rao, A.V.; De, A. Numerical modeling of friction stir welding using the tools with polygonal pins. Def. Technol. 2015, 11, 229-236. [CrossRef]

21. Dubourg, L.; Merati, A.; Jahazi, M. Process optimisation and mechanical properties of friction stir lap welds of 7075-T6 stringers on 2024-T3 skin. Mater. Des. 2010, 31, 3324-3330. [CrossRef]

22. Elatharasan, G.; Kumar, V.S.S. Modelling and optimization of friction stir welding parameters for dissimilar aluminium alloys using RSM. Procedia Eng. 2012, 38, 3477-3481. [CrossRef]

23. Rhodes, C.G.; Mahoney, M.W.; Bingel, W.H.; Spurling, R.A.; Bampton, C.C. Effects of friction stir welding on microstructure of 7075 aluminum. Scr. Mater. 1997, 36, 69-75. [CrossRef]

24. Mahoney, M.W.; Rhodes, C.G.; Flintoff, J.G.; Spurling, R.A.; Bingel, W.H. Properties of friction-stir-welded 7075 T651 aluminum. Metall. Mater. Trans. A 1998, 29, 1955-1964. [CrossRef]

25. Thomas, W.M.; Threadgill, P.L.; Nicholas, E.D. Feasibility of friction stir welding steel. Sci. Technol. Weld. Join. 1999, 4, 365-372. [CrossRef]

26. Lohwasser, D.; Chen, Z. Friction Stir Welding: From Basics to Applications; Woodhead Publishing Ltd.: Cambridge, UK, 2009.

27. DebRoy, T.; Bhadeshia, H.K.D.H. Friction stir welding of dissimilar alloys-A perspective. Sci. Technol. Weld. Join. 2010, 15, 266-270. [CrossRef]

28. Kumar, N.; Yuan, W.; Mishra, R.S. A framework for friction stir welding of dissimilar alloys and Materials. In Friction Stir Welding of Dissimilar Alloys and Materials; Kumar, N., Yuan, W., Mishra, R.S., Eds.; Butterworth-Heinemann: Oxford, UK, 2015; pp. 15-33.

29. Okamura, H.; Aota, K. Joining of dissimilar materials with friction stir welding. Weld. Int. 2004, 18, 852-860. [CrossRef]

30. Kumar, N.; Yuan, W.; Mishra, R.S. Friction stir welding of dissimilar alloys. In Friction Stir Welding of Dissimilar Alloys and Materials; Kumar, N., Yuan, W., Mishra, R.S., Eds.; Butterworth-Heinemann: Oxford, UK, 2015; pp. 43-69. 
31. Palanivel, S.; Nelaturu, P.; Glass, B.; Mishra, R.S. Friction stir additive manufacturing for high structural performance through microstructural control in an Mg based WE43 alloy. Mater. Des. 2015, 65, 934-952. [CrossRef]

32. Lim, Y.C.; Sanderson, S.; Mahoney, M.; Wang, Y.; Chen, J.; David, S.A.; Feng, Z. Fabrication of thick multilayered steel structure using A516 Grade 70 by multipass friction stir welding. Sci. Technol. Weld. Join. 2016, 21, 564-569. [CrossRef]

33. Taendl, J.; Nambu, S.; Inoue, J.; Enzinger, N.; Koseki, T. Friction stir welding of multilayered steel. J. Sci. Technol. Weld. Join. 2012, 17, 244-253. [CrossRef]

34. Aditya, A.V.; Arora, H.S.; Mukherjee, S. Corrosion behavior of ZrTiCuNiBe bulk metallic glass subjected to friction stir processing. J. Non. Cryst. Solids 2015, 425, 124-129. [CrossRef]

35. Tang, W.; Guo, X.; McClure, J.C.; Murr, L.E.; Nunes, A. Heat input and temperature distribution in friction stir welding. J. Mater. Process. Manuf. Sci. 1998, 7, 163-172. [CrossRef]

36. Imam, M.; Biswas, K.; Racherla, V. On use of weld zone temperatures for online monitoring of weld quality in friction stir welding of naturally aged aluminium alloys. Mater. Des. 2013, 52, 730-739. [CrossRef]

37. Kim, Y.G.; Fujii, H.; Tsumura, T.; Komazaki, T.; Nakata, K. Three defect types in friction stir welding of aluminum die casting alloy. Mater. Sci. Eng. A 2006, 415, 250-254. [CrossRef]

38. Reza-E-Rabby, M.; Tang, W.; Reynolds, A.P. Effect of tool pin features on process response variables during friction stir welding of dissimilar aluminum alloys. Sci. Technol. Weld. Join. 2015, 20, 425-432. [CrossRef]

39. Costa, M.I.; Verdera, D.; Costa, J.D.; Leitao, C.; Rodrigues, D.M. Influence of pin geometry and process parameters on friction stir lap welding of AA5754-H22 thin sheets. J. Mater. Process. Technol. 2015, 225, 385-392. [CrossRef]

40. Mishra, R.S.; Ma, Z.Y. Friction stir welding and processing. Mater. Sci. Eng. R Rep. 2005, 50, 1-78. [CrossRef]

41. Thomas, W.M.; Johnson, K.I.; Wiesner, C.S. Friction stir welding-recent developments in tool and process technologies. Adv. Eng. Mater. 2003, 5, 485-490. [CrossRef]

42. Thomas, W.M.; Staines, D.G.; Norris, I.M.; de Frias, R. Friction stir welding tools and developments. Weld. World 2003, 47, 10-17. [CrossRef]

43. Thompson, B.T. Tool Degradation Characterization in the Friction Stir Welding of Hard Metals. Master's Thesis, Ohio State University, Columbus, OH, USA, 2010.

44. Chu, W.S. Influence of different anvil back plates on heat dissipation velocity of the micro-friction stir welding process. Appl. Mech. Mater. 2015, 786, 415-420. [CrossRef]

45. Kahl, S.; Osikowicz, W. Composite aluminum-copper sheet material by friction stir welding and cold rolling. J. Mater. Eng. Perform. 2013, 22, 2176-2184. [CrossRef]

46. Kadlec, M.; Růžek, R.; Nováková, L. Mechanical behaviour of AA 7475 friction stir welds with the kissing bond defect. Int. J. Fatigue 2015, 74, 7-19. [CrossRef]

47. Colegrove, P.A. Modelling of friction stir welding. Ph.D. Thesis, University of Cambridge, Cambridge, UK, 2003.

48. Colegrove, P.A.; Shercliff, H.R. Experimental and numerical analysis of aluminium alloy 7075-T7351 friction stir welds. Sci. Technol. Weld. Join. 2003, 8, 360-368. [CrossRef]

49. Kittima, S.; Mutoh, Y.; Miyashita, Y.; Seo, N. Fatigue strength estimation based on local mechanical properties for aluminum alloy. Materials 2017, 10, 7-9.

50. Hori, H.; Makita, S.; Hino, H. Friction Stir Welding of Rolling Stock for Subway. In Proceedings of the First International Symposium on Friction Stir Welding, Thousand Oaks, CA, USA, 14-16 June 1999; pp. 113-120.

51. Bussu, G.; Irving, P.E. The role of residual stress and heat affected zone properties on fatigue crack propagation in friction stir welded 2024-T351 aluminium joints. Int. J. Fatigue 2003, 25, 77-88. [CrossRef]

52. Magnusson, L.; Kallman, L. Mechanical Properties of Friction Stir Welds in Thin Sheets of Aluminum 20224, 6013 and 7475. In Proceedings of the Second International Symposium on Friction Stir Welding, Gothenburg, Sweden, 26-28 June 2000.

53. Babu, S.; Ram, G.D.J.; Venkitakrishnan, P.V.; Reddy, G.M.; Rao, K.P. Microstructure and mechanical properties of friction stir lap welded aluminum alloy AA2014. J. Mater. Sci. Technol. 2012, 28, 414-426. [CrossRef]

54. Tsujikawa, M.; Somekawa, H.; Higashi, K.; Iwasaki, H.; Hasegawa, T.; Mizuta, A. Fatigue of welded magnesium alloy joints. Mater. Trans. 2004, 45, 419-422. [CrossRef]

55. Kumar, N.; Mishra, R.S.; Baumann, J.A. Residual Stresses in Friction Stir Welding; Butterworth-Heinemann: Oxford, UK, 2013. 
56. Lemmen, H.J.K.; Alderliesten, R.C.; Pieters, R.R.G.M.; Benedictus, R.; Pineault, J.A. Yield strength and residual stress measurements on friction-stir-welded aluminum alloys. J. Aircr. 2010, 47, 1570-1583. [CrossRef]

57. Suenger, S.; Kreissle, M.; Kahnert, M.; Zaeh, M.F. Influence of process temperature on hardness of friction stir welded high strength aluminum alloys for aerospace applications. Procedia CIRP 2014, 24, 120-124. [CrossRef]

58. Khodir, S.A.; Shibayanagi, T.; Naka, M. Control of hardness distribution in friction stir welded AA2024-T3 aluminum alloy. Mater. Trans. 2006, 47, 1560-1567. [CrossRef]

59. Ma, Z.Y.; Sharma, S.R.; Mishra, R.S. Microstructural modification of As-cast Al-Si-Mg alloy by friction stir processing. Metall. Mater. Trans. A Phys. Metall. Mater. Sci. 2006, 37, 3323-3336. [CrossRef]

60. Ghorbanzade, T.; Soltanipour, A.; Dehghani, K.; Chabok, A. Microstructural evolutions and mechanical properties of friction stir welded AA2024-3. Proc. Inst. Mech. Eng. Part L J. Mater. Des. Appl. 2016, 230, 75-87. [CrossRef]

61. Wulff, A. Friction Stir Welding Defects, Analysis and Correction: History and Defects of Solid-state Welding; Technical Report; South Dakota School of Mines \& Technology: Rapid City, SD, USA, 27 July 2013.

62. Boldsaikhan, E.; Corwin, E.; Logar, A.; McGough, J.; Arbegast, W. Detecting Wormholes in Friction Stir Welds from Welding Feedback Data. In Proceedings of the 42nd Midwest Instruction and Computing Symposium (MICS 2009), Rapid City, SD, USA, 17-18 April 2009; p. 45.

63. Shirazi, H.; Kheirandish, S.; Safarkhanian, M.A. Effect of process parameters on the macrostructure and defect formation in friction stir lap welding of AA5456 aluminum alloy. Measurement 2015, 76, 62-69. [CrossRef]

64. Mandache, C.; Levesque, D.; Dubourg, L.; Gougeon, P. Non-destructive detection of lack of penetration defects in friction stir welds. Sci. Technol. Weld. Join. 2012, 17, 295-303. [CrossRef]

65. Gray, T. National Science Foundation Industry/University Cooperative Research Program-Annual Report; National Science Foundation: Alexandria, VA, USA, 2008.

66. Oosterkamp, A.; Oosterkamp, L.; Nordeide, A. 'Kissing Bond' phenomena in solid-state welds of aluminum alloys. Weld. J. 2004, 83, 225-231.

67. Delrue, S.; Tabatabaeipour, M.; Hettler, J.; Van Den Abeele, K. Applying a nonlinear, pitch-catch, ultrasonic technique for the detection of kissing bonds in friction stir welds. Ultrasonics 2016, 68, 71-79. [CrossRef]

68. Ruzek, R.; Kadlec, M. Friction stir welded structures: Kissing bond defects Friction stir welded structures: Kissing bond defects. Int. J. Terrasp. Sci. Eng. 2014, 6, 77-83.

69. Morisada, Y.; Imaizumi, T.; Fujii, H. Clarification of material flow and defect formation during friction stir welding. Sci. Technol. Weld. Join. 2015, 20, 130-137. [CrossRef]

70. Bisadi, H.; Tour, M.; Tavakoli, A. The influence of process parameters on microstructure and mechanical properties of friction stir welded Al 5083 alloy lap joint. Am. J. Mater. Sci. 2011, 1, 93-97. [CrossRef]

71. Pao, P.S.; Gill, S.J.; Feng, C.R.; Sankaran, K.K. Corrosion-fatigue crack growth in friction stir welded Al 7050. Scr. Mater. 2001, 45, 605-612. [CrossRef]

72. Yamamoto, M.; Gerlich, A.; North, T.H.; Shinozaki, K. Mechanism of cracking in AZ91 friction stir spot welds. Sci. Technol. Weld. Join. 2007, 12, 208-216. [CrossRef]

73. Yamamoto, M.; Gerlich, A.; North, T.H.; Shinozaki, K. Cracking in dissimilar Mg alloy friction stir spot welds. Sci. Technol. Weld. Join. 2008, 13, 583-592. [CrossRef]

74. Celik, S.; Cakir, R. Effect of friction stir welding parameters on the mechanical and microstructure properties of the Al-Cu butt joint. Metals 2016, 6, 133. [CrossRef]

75. Fowler, S.; Toumpis, A.; Galloway, A. Fatigue and bending behaviour of friction stir welded DH36 steel. Int. J. Adv. Manuf. Technol. 2016, 84, 2659-2669. [CrossRef]

76. Ericsson, M.; Jin, L.; Sandstrom, R. Fatigue properties of friction stir overlap welds. Int. J. Fatigue 2007, 29, 57-68. [CrossRef]

77. Infante, V.; Braga, D.F.O.; Duarte, F.; Moreira, P.M.G.; De Freitas, M.; De Castro, P.M.S.T. Study of the fatigue behaviour of dissimilar aluminium joints produced by friction stir welding. Int. J. Fatigue 2016, 82, 310-316. [CrossRef]

78. Taheri, H. Classification of Nondestructive Inspection Techniques with Principal Component Analysis (PCA) for Aerospace Application. In Proceedings of the ASNT 26th Research Symposium, Jacksonville, FL, USA, 13-16 March 2017; pp. 219-227. 
79. Joshi, V.; Balasubramaniam, K.; Prakash, R.V. Study of Defects in Friction Stir Welded Aa 5083 By Radiography, Ultrasonic and Phased Array Ultrasonic Technique. In Proceedings of the National Seminar\& Exhibition on Non-Destructive Evaluation, Chennai, India, 8-10 December 2011; p. 7.

80. Saravanan, T.; Lahiri, B.B.; Arunmuthu, K.; Bagavathiappan, S.; Sekhar, A.S. Non-destructive evaluation of friction stir welded joints by X-ray radiography and infrared thermography. Procedia Eng. 2014, 86, 469-475. [CrossRef]

81. Schmidt, H.; Hattel, J.; Wert, J. An analytical model for the heat generation in friction stir welding. Model. Simul. Mater. Sci. Eng. 2004, 12, 143-157. [CrossRef]

82. Serio, L.M.; Palumbo, D.; Galietti, U.; De Filippis, L.A.C.; Ludovico, A.D. Monitoring of the friction stir welding process by means of thermography. Nondestruct. Test. Eval. 2016, 31, 371-383. [CrossRef]

83. Rubtsov, V.E.; Kolubaev, E.A.; Tarasov, S.Y.; Vasilyev, P.A.; Bakshaev, V.A. Thermography inspection of friction stir welding. AIP Conf. Proc. 2014, 1623, 535-538.

84. Smith, R.A. The potential for friction stir weld inspection using transient eddy currents. Insight Non-Destr. Test. Condition Monit. 2005, 47, 133-143. [CrossRef]

85. Rosado, L.S.; Santos, T.G.; Piedade, M.; Ramos, P.M.; Vilaça, P. Advanced technique for non-destructive testing of friction stir welding of metals. Meas. J. Int. Meas. Confed. 2010, 43, 1021-1030. [CrossRef]

86. Nagy, P.B.; Adler, L. Ultrasonic NDE of solid-state bonds: Inertia and friction welds. J. Nondestruct. Eval. 1988, 7, 199-215. [CrossRef]

87. Tittmann, B.R.; Hosten, B.H. A self-calibrating technique for the ultrasonic discrimination of solid-state welds. J. Nondestruct. Eval. 1988, 7, 191-197. [CrossRef]

88. Tabatabaeipour, M.; Hettler, J.; Delrue, S.; Van Den Abeele, K. Nondestructive ultrasonic inspection of friction stir welds. Phys. Procedia 2015, 70, 660-663. [CrossRef]

89. Thomas, G.H.; Spingarn, J.R. Ultrasonic evaluation of solid-state welds. J. Nondestr. Eval. 1988, 7, $227-235$. [CrossRef]

90. Stepinski, T.; Lingvall, F.; Wennerstrom, E.; Wu, P. Inspection of Copper Canisters for Spent Nuclear Fuel by Means of Ultrasound; Technical Report; Uppsala University: Uppsala, Sweden, 2004.

91. Taheri, H. Utilization of Non-Destructive Testing (NDT) Methods for Composite Material Inspection (Phased Array Ultrasonic). Master's Thesis, South Dakota State University, Brookings, SD, USA, 2014.

92. Taheri, H.; Du, J.; Delfanian, F. Experimental Observation of Phased Array Guided Wave Application in Composite Materials. Mater. Eval. 2017, 75, 1308-1316.

93. Taheri, H.; Delfanian, F.; Du, J. Acoustic Emission and Ultrasound Phased Array Technique for Composite Material Evaluation. In Proceedings of the ASME 2013 International Mechanical Engineering Congress and Exposition, San Diego, CA, USA, 15-21 November 2013; p. V001T01A015.

94. Taheri, H.; Ladd, K.M.; Delfanian, F.; Du, J. Phased Array Ultrasonic Technique Parametric Evaluation for Composite Materials. In Proceedings of the ASME 2014 International Mechanical Engineering Congress and Exposition, Montreal, QC, Canada, 14-20 November 2014; p. V013T16A028.

95. Fortunato, J.; Anand, C.; Braga, D.F.O.; Groves, R.M.; Moreira, P.M.G.P.; Infante, V. Friction stir weld-bonding defect inspection using phased array ultrasonic testing. Int. J. Adv. Manuf. Technol. 2017, 93, 3125-3134. [CrossRef]

96. Ditchburn, R.J.; Ibrahim, M.E. Ultrasonic Phased Arrays for the Inspection of Thick-Section Welds; Report DSTO-TN-0911; Defense Science and Technology Organization: Victoria, Australia, 2009.

97. Bird, C.R. Ultrasonic phased array inspection technology for the evaluation of friction stir welds. Insight Non-Destr. Test. Condition Monit. 2004, 46, 31-36. [CrossRef]

98. Moles, M.D.C.; Bird, C.R.; Herzog, P.; Armitt, T.; Ciorau, P.; Roberts, R.; Davis, M. Introduction to Phased Array Ultrasonic Technology Applications: Olympus Guideline; Olympus: Waltham, MA, USA, 2017.

99. Huggett, D.J.; Dewan, M.W.; Wahab, M.A.; Okeil, A.; Liao, T.W. Phased array ultrasonic testing for post-weld and on-line detection of friction stir welding defects. Res. Nondestruct. Eval. 2016, 28, 187-210. [CrossRef]

100. Scruby, C.B.; Drain, L.E. Laser Ultrasonics Techniques and Applications; CRC Press: Boca Raton, FL, USA, 1990.

101. Zhou, Z.; Zhang, K.; Zhou, J.; Sun, G.; Wang, J. Application of laser ultrasonic technique for non-contact detection of structural surface-breaking cracks. Opt. Laser Technol. 2015, 73, 173-178. [CrossRef]

102. Broda, D.; Staszewski, W.J.; Martowicz, A.; Uhl, T.; Silberschmidt, V.V. Modelling of nonlinear crack-wave interactions for damage detection based on ultrasound-A review. J. Sound Vib. 2014, 333, 1097-1118. [CrossRef] 
103. Solodov, I.; Krohn, N.; Busse, G. Nonlinear Ultrasonic NDT for Early Defect Recognition and Imaging. In Proceedings of the 10th European Conference on Non-Destructive Testing (ECNDT), Moscow, Russia, 7-11 June 2010; pp. 1-25.

104. Sewell, N.T.; Wright, J.C.S.; Wright, J.R.; Mottram, T.D. Automated non-linear acoustic NDT of Friction Stir Welds. Available online: http://gamechangingndt.com/wp-content/uploads/2016/01/Automated-non-linearacoustic-NDT-of-Friction-Stir-Welds-Sewell-Wright-Wright-Mottram-Theta-Technologies.pdf (accessed on 15 April 2019).

105. Tracy, N.A.; Moore, P.O. Liquid penetrant testing. In Nondestructive Testing Handbook, 3rd ed.; ASNT: Columbus, OH, USA, 1999.

106. Chauveau, D. Review of NDT and process monitoring techniques usable to produce high-quality parts by welding or additive manufacturing. Weld. World 2018, 62, 1097-1118. [CrossRef]

107. Burford, D.; Britos, P.G.; Boldsaikhan, E.; Brown, J. Evaluation of Friction Stir Weld Process and Properties for Aerospace Application. In Proceedings of the Federal Aviation Administration Joint Advanced Materials \& Structures (JAMS) Center of Excellence 6th Annual Technical Review Meeting, Seattle, WA, USA, 19-20 May 2010; pp. 1-27.

108. Soundararajan, V.; Atharifar, H.; Kovacevic, R. Monitoring and processing the acoustic emission signals from the friction-stir-welding process. Proc. Inst. Mech. Eng. Part B J. Eng. Manuf. 2006, 220, 1673-1685. [CrossRef]

109. Subramaniam, S.; S, N.; S, D.A. Acoustic emission-based monitoring approach for friction stir welding of aluminum alloy AA6063-T6 with different tool pin profiles. Proc. Inst. Mech. Eng. Part B J. Eng. Manuf. 2013, 227, 407-416. [CrossRef]

110. Zeng, W.; Wu, H.L.; Zhang, J. Effect of tool wear on microstructure, mechanical properties and acoustic emission of friction stir welded $6061 \mathrm{Al}$ alloy. Acta Metall. Sin. (English Lett.) 2006, 19, 9-19. [CrossRef]

111. Mehta, M.; Chatterjee, K.; De, A. Monitoring torque and traverse force in friction stir welding from input electrical signatures of driving motors. Sci. Technol. Weld. Join. 2013, 18, 191-197. [CrossRef]

112. Jene, T.; Dobmann, G.; Wagner, G.; Eifler, D. Monitoring of the friction stir welding process to describe parameter effects on joint quality. Weld. World 2008, 52, 47-53. [CrossRef]

113. Hattingh, D.G.; van Niekerk, T.I.; Blignault, C.; Kruger, G.; James, M.N. Analysis of the FSW force footprint and its relationship with process parameters to optimise weld performance and tool design. Weld. World 2004, 48, 50-58. [CrossRef]

114. Kleiner, D.; Bird, C.R. Signal processing for quality assurance in friction stir welds. Insight Non-Destr. Test. Condition Monit. 2004, 46, 85-87. [CrossRef]

115. Sinha, P.; Muthukumaran, S.; Sivakumar, R.; Mukherjee, S.K. Condition monitoring of first mode of metal transfer in friction stir welding by image processing techniques. Int. J. Adv. Manuf. Technol. 2008, 36, 484-489. [CrossRef]

116. Ranjan, R.; Khan, A.R.; Parikh, C.; Jain, R.; Mahto, R.P.; Pal, S.; Pal, S.K.; Chakravarty, D. Classification and identification of surface defects in friction stir welding: An image processing approach. J. Manuf. Process. 2016, 22, 237-253. [CrossRef]

117. Fleming, P.; Lammlein, D.; Wilkes, D.; Fleming, K.; Bloodworth, T.; Cook, G.; Strauss, A.; DeLapp, D.; Lienert, T.; Bement, M.; Prater, T. In-process gap detection in friction stir welding. Sens. Rev. 2008, 28, 62-67. [CrossRef]

118. Baraka, A.; Panoutsos, G.; Cater, S. A real-time quality monitoring framework for steel friction stir welding using computational intelligence. J. Manuf. Process. 2015, 20,137-148. [CrossRef]

(C) 2019 by the authors. Licensee MDPI, Basel, Switzerland. This article is an open access article distributed under the terms and conditions of the Creative Commons Attribution (CC BY) license (http://creativecommons.org/licenses/by/4.0/). 